\title{
Sextant Core Biopsy
}

National Cancer Institute

\section{Source}

National Cancer Institute. Sextant Core Biopsy. NCI Thesaurus. Code C142183.

A prostate biopsy collection protocol in which 6 biopsies are obtained in the parasagittal plane halfway between the lateral border and midline of the prostate on both right and left sides from the base, mid-gland, and apex. 